\title{
La revista Micro (1940-1949) y la crítica cinematográfica y radiofónica en Colombia
}

\section{Contribution to a history of film and radio criticism in Colombia: journal micro, 1940-1949}

DOI:https://doi.org/10.25100/hye.v16i54.9913

Artículo recibido: 01-10-2018 Artículo aceptado: 29-01-2020

\section{Andrés Villegas Vélez}

Antropólogo graduado de la Universidad de Antioquia, realizó estudios de maestría y doctorado en historia en la Universidad Nacional de Colombia Sede Medellín y actualmente es docente de la misma institución.

Universidad Nacional de Colombia, Sede Medellín.

Correo electrónico: aavilleg@unal.edu.co

ORCID: 0000-0001-9024-4479

\section{Catalina Castrillón Gallego}

Historiadora graduada de la Universidad Nacional de Colombia, sede Medellin y Doctora en Historia por la misma institución. Actualmente es profesora asociada de la Universidad Pontificia Bolivariana seccional Medellín.

Universidad Pontificia Bolivariana seccional Medellín.

Correo electrónico: catalina.castrillon@upb.edu.co

ORCID: 0000-0003-1357-6693

Forma de citar este artículo: Villegas Vélez, Andrés y Catalina Castrillón Gallego. "La revista Micro (1940-1949) y la crítica cinematográfica y radiofónica en Colombia" Historia y Espacio, vol. 16 n 54 (2020): 209 - 236. Doi.org/10.25100/hye.v16i54.9913.

Artículo Tipo 2: de reflexión 


\section{Resumen}

Este artículo se concentra en la revista Micro dirigida por Camilo Correa y editada en Medellín entre 1940 y 1949. A través de su revisión, se describe e interpreta el ejercicio crítico que en ella se planteó, y que buscó contribuir a la profesionalización del cine y la radio nacionales, lo que incluía su consolidación como industrias rentables económicamente, pero también relevantes artística y técnicamente. Esta profesionalización requería, también, de un público conocedor para lo cual la labor formativa de los medios impresos era fundamental. En este sentido, la crítica para Correa implicaba tanto el comentario sobre los contenidos como la reflexión sobre las condiciones que los hacían posibles.

Palabras clave: Micro, cine, radiodifusión, historia de los medios, crítica de medios.

\section{Abstract}

The article focuses on the journal Micro, which was edited by Camilo Correa. By means of a critical review, the article describes and interprets the critical practice done in the journal. The latter aimed at contributing to the professionalization of film and radio, which included both its consolidation as a profitable industry and the establishment of its artistic and technical relevance. Such a professionalization also required a well-prepared audience, in which formation the work of the journals became crucial. Therefore, criticism for Correa meant both the review of the contents and thoughts on the conditions that made the former possible.

Keywords: Micro, cinema, radio broadcasting, history of the media, criticism of the media. 


\section{Andrés Villegas Vélez, Catalina Castrillón Gallego}

\section{La revista Micro (1940-1949) y la crítica cinematográfica y radiofónica en Colombia}

\section{Introducción}

La comprensión histórica de los medios de comunicación masiva requiere del estudio de las diferentes prácticas, discursos y agentes sociales que los forman. Sin embargo, son escasas las investigaciones sobre la crítica de medios y los espacios en que se ha ejercido. En Colombia, se han publicado algunos trabajos que examinan la crítica cinematográfica ${ }^{1}$, pero la labor de quienes reflexionaron sobre la radio desde los periódicos, las revistas y otros medios no ha generado igual interés.

La mayoría de las investigaciones mencionadas se ha ocupado de críticos o publicaciones seriadas. Zuluaga ${ }^{2}$ realizó una revisión panorámica de las revistas sobre cine y planteó la existencia de cuatro periodos. El Cinematógrafo (1908) abriría el primero, el cual tendría su momento de mayor exuberancia cuantitativa en la siguiente década, y finalizaría en los años veinte, la mayoría de las revistas de este periodo, así como del siguiente, serían editadas por distribuidores o exhibidores, lo cual implicaba que fueron más cercanas a la publicidad que a la crítica propiamente dicha. Un segundo momento estaría marcado por la aparición en 1936 de Cine de hoy publicada por Cine Colombia ${ }^{3}$, a la que se sumarían, en 1940, Micro y luego Cine y Cinema-Gráfico. En las décadas de 1950 y 1960, la crítica encontraría su lugar en numerosos

1 Se destaca especialmente el número 22 de la revista Cuadernos de Cine Colombiano, dedicado a la crítica. También están: Camilo Calderón Acero, "Páginas de cine: el aporte desde Bogotá" en Bogotáfilmica. Ensayos sobre cine y patrimonio cultural, editado por Sergio Becerra (Bogotá: Alcaldía Mayor de Bogotá, 2012), 270-297; María Antonia Vélez, "Transmutaciones de una caja negra: lo nacional en el cine colombiano, según los críticos”, en Los pasos sobre las huellas: ensayos sobre crítica de arte (Bogotá: Universidad de los Andes y Ministerio de Cultura, 2007), 63-80; Pedro Adrián Zuluaga, "Revistas de cine en Colombia. La otra misma historia”, Cuadernos de Cine Colombiano, n. 6 (2005): 32-49; Pedro Adrián Zuluaga, Cine colombiano: cánones y discursos dominantes (Bogotá: Cinemateca Distrital, 2013) y Pedro Adrián Zuluaga. "Cine colombiano: las garras de oro del canon", Mediaciones, n. ${ }^{\circ} 14$ (2015): 150-161.

2 Zuluaga, "Revistas de cine en Colombia”, 32-49.

3 Cine Colombia es una empresa exhibidora fundada en la ciudad de Medellín en 1927. Para la fecha ya era una de las principales compañías de este tipo en el país gracias, en buena medida, a su apuesta por el cine de Hollywood frente al cine europeo. Para información al respecto 
periódicos, en revistas culturales como Mito y en publicaciones especializadas como Guiones y Cine(mes); se empieza a ejercer una crítica más erudita y en ocasiones comprometida políticamente. Y, a partir de los años setenta es posible apreciar la diversificación de la crítica y de las publicaciones en las que se ejercía, a la par que se puede inferir algún grado de profesionalización de los críticos. Cabe agregar un quinto momento a partir de finales de la década de 1990 con la irrupción de la crítica online.

Lastimosamente, la caracterización de las publicaciones dedicadas a la radiodifusión es una tarea pendiente. No obstante, se cuenta con un artículo y un libro ${ }^{4}$ que permiten reconstruir parte del cubrimiento que hicieron los medios impresos a la radio colombiana en sus primeras décadas de funcionamiento. Es posible afirmar que los periódicos y las revistas le prestaron atención a este medio desde mediados de los veinte; en un primer momento se hizo énfasis en la novedad técnica y, luego, la atención fue para su consolidación como industria y los programas emitidos. Estas publicaciones se pueden dividir en tres grandes grupos: los impresos que divulgaban información variada y en los cuales las notas y la publicidad sobre radio eran ocasionales; las publicaciones seriadas que crearon secciones especializadas como la Revista Chapinero en 1928, el periódico Mundo al Día en 1929 y, posteriormente, los periódicos El Liberal (1944) y El Espectador (1945) y la revista Semana (1947); y el tercero, las revistas dedicadas a uno o varios aspectos de la radiodifusión, entre ellas se encontraban Radio (1933-1936) de la Liga Colombiana de Radioaficionados que se concentró en cuestiones técnicas y científicas, los boletines de programación de las emisoras culturales y las revistas dedicadas al cubrimiento de la radio como industria y espectáculo: Ondas Radio-Revista (1938-1941) y Micro (1940-1949).

El cubrimiento de las actividades cinematográficas - realización, distribución y exhibición-, durante la década de 1940, se desmarcó parcialmente de la información producida por los exhibidores y distribuidores en las publicaciones de las décadas anteriores, aunque estos fueron importantes anunciantes, por lo cual su autonomía no fue completa. No se trataba ya de

se puede ver: Álvaro Concha Henao, Historia social del cine en Colombia, tomo 1, 1897-1929 (Bogotá: Black Maria, 2014), 478-484.

4 Catalina Castrillón Gallego, "La actividad radial colombiana a través de algunos periódicos y revistas, 1928-1950”. Revista Colombiana de Antropología 47, n.o 1 (2011): 137-154 y Catalina Castrillón Gallego, Todo viene y todo sale por las ondas. Formación y consolidación de la radiodifusión colombiana, 1929-1954 (Medellín: Universidad de Antioquia - Universidad Nacional de Colombia, sede Medellín, 2015), 10-14. 
promocionar una película en la que se había invertido un importante capital, sino de brindar información sobre el mundo del espectáculo.

En cuanto a la radiodifusión, la principal transformación de las revistas de esta década fue el desplazamiento de la preocupación por los problemas técnicos vinculados a la recepción de una tecnología novedosa, la narración de sus posibilidades o las curiosas situaciones surgidas por el apasionamiento de los oyentes noveles, por su desenvolvimiento como industria del entretenimiento, que producía programas de diverso tipo, se sustentaba económicamente en la publicidad y atraía a grandes audiencias gracias a las estrellas musicales. De esta forma, la información sobre las películas, los programas de radio y las estrellas de ambos medios hacía parte con frecuencia de secciones y publicaciones que también daban a conocer la programación de conciertos u obras de teatro. Se trataba, entonces, de una suerte de circuito artístico y del espectáculo que vinculaba medios de comunicación, artes escénicas e industria fonográfica, y formaba un ecosistema mediático, en el cual era frecuente que los artistas retroalimentaran su fama y reconocimiento pasando del canto a la actuación y viceversa.

En este artículo nos concentraremos en Micro, en tanto es una fuente indispensable para, desde la historia, pensar el cine, la radio y la crítica de ambos medios en la Colombia de mediados del siglo pasado. En términos metodológicos, se hizo una revisión exhaustiva de los 62 números de la revista, los cuales están disponibles en la Sala de Patrimonio Documental del Centro Cultural Biblioteca Luis Echavarría Villegas de la Universidad Eafit en la ciudad de Medellín. Esta revisión buscó inventariar y analizar los artículos que sobre ambos medios se publicaron en la revista, además de caracterizar los autores que los publicaron e identificar las secciones que conformaron la publicación y sus cambios a través del tiempo. También, se contrastó la información obtenida con la de algunos periódicos de la ciudad de Medellín contemporáneos de Micro y con la bibliografía disponible sobre problemas cercanos al interés de este artículo. Se identificaron dos ejes relevantes de análisis: la práctica y las representaciones sobre la crítica y los debates que, sobre la industria radiofónica y la ausencia de una industria cinematográfica colombiana, aparecieron en la revista. Es necesario advertir que la crítica de fuentes realizada no busca corroborar o desmentir la veracidad de los planteamientos publicados, sino que el foco estuvo en cómo se criticaron ambos medios y en cuáles fueron las representaciones que sobre la crítica misma y sobre la industria se elaboraron. En este sentido, el artículo se enmarca en la historia cultural de lo social, tal 
como ha sido formulada por Roger Chartier, es decir, la historia de cómo se ha construido sentido compartido y debatido sobre obras, prácticas y representaciones en sociedades concretas ${ }^{5}$.

\section{Camilo Correa y la revista Micro}

Camilo Correa (1913-1990) ha sido considerado el personaje más importante del comentario cinematográfico de la década de $1940^{6}$. Martínez Pardo consideró que su mérito fue doble; por un lado, planteó la necesidad de rechazar el lugar común de tomar a la industria mexicana como el modelo privilegiado para el cine nacional; por el otro, abandonó cierta noción voluntarista del capital que había hecho carrera y afirmó que las inversiones llegarían cuando se pudieran garantizar las ganancias de los socios, lo cual hacía necesario que las películas atrajeran al público. Martínez cita una entrevista con Correa, en la que niega haber cumplido el rol de crítico y se autodefine como un "opinante" Asimismo, su labor no estuvo desligada del ejercicio de la crítica radial, tanto en la sección "En picada” del periódico El Colombiano como en Micro. Esta revista se editó entre los años 1940 y 1949, aunque con frecuentes interrupciones, como lo reconoció su fundador y "hombre orquesta" Camilo Correa:

MICRO vio la luz - en calidad de periodiquito semanal de 8 (sic) págnasel 15 de febrero de 1940 [...]. Pero... resulta que la vida de la revista ha sido de lo más precario que pueda imaginarse: un sietemesino jamás hubiera dado todas las bregas que MICRO dio - y continúa dando - al ciudadano que se metió a ser padre-madre de esta publicación. Así que hay que olvidarse de los años en rigor de cronología: de semanario pasó a (sic) decadal; de ahí a mensual con la idea de ser mensual; pero ni los establecimientos impresores ni los "camaradas" anunciadores se prestaron a la aventura. La revista salió cada que Dios le ayudó. Y terminó por declarar su primera huelga por allá a fines del 41 o algo así. Reapareció en julio del 43, ya con pretensiones de revista dizque buena [...]. Pero de nuevo la tipografía se encargó de garantizar que la revista no saliera puntualmente ni una sola vez. Y de ese julio del 43 al septiembre del 44, o sea en 14 meses ocho ediciones: del número 52 al 59 [...]. La guerra fue el pretexto, y no volvió a

5 Roger Chartier, El mundo como representación. Historia cultural entre práctica y representación (Barcelona: Gedisa, 1996) y Roger Chartier, La historia o la lectura del tiempo (Barcelona: Gedisa, 2007), 52.

6 Hernando Martínez Pardo, Historia del cine colombiano (Bogotá: América Latina, 1978), 144.

7 Martínez Pardo, Historia del cine, 143. 
quemar ramo vendido. MICRO regresó al ostracismo, contabilizando una buena cantidad de pesos en su saldo rojo ${ }^{8}$.

A lo que agregó: [...] un año de revista mensual está formado por 12 números. O sea que 60 números de revista - si la revista es mensual, y MICRO lo es - forman cinco años, a menos que 12 por 5 no dé 60 o que 60 dividido por 12 no dé CINCO ${ }^{9}$. Revisando con detenimiento la revista es posible plantear que efectivamente tuvo tres etapas: la primera comprende del número 1 al 51, publicados entre febrero de 1940 y mayo de 1941, la cual se caracterizó por una periodicidad mayor, por un número de páginas relativamente reducido y porque Correa se encargaba de escribir todas las secciones, salvo las colaboraciones de Luis Miguel de Zulategi, de origen español, pero afincado en Medellín, y Luis Lalinde Botero, ambos dedicados al comentario musical que tuvo un importante espacio en esta publicación y ha sido analizado por Carolina Santamaría-Delgado ${ }^{10} \mathrm{y}$ compilado por Fernando Gil Araque ${ }^{11}$ dada su importancia como fuente para la discusión sobre la música nacional colombiana durante la primera mitad del siglo XX, aspecto que no será tratado en este artículo, salvo cuando se relacione con el cine o la radiodifusión.

Un segundo momento está comprendido entre el número 52, publicado en julio de 1943, y el número 59 que apareció en septiembre de 1944; en este lapso la revista aspiró a aparecer mensualmente, pero no lo logró. Se destaca el incremento en el número de páginas y el gran número de colaboradores, algunos de fuera de Colombia; también asumió una defensa apasionada del "folklore patrio". En la tercera etapa, de solo tres números, editados entre mayo y julio de 1949, disminuyó el interés por el folclor y el número de redactores, como se les denominó, aunque se incluyeron algunos de Medellín, Bogotá, Cali, Barranquilla, Hollywood, Londres, Nueva York, París, Madrid, Buenos Aires y México. Su distribución alcanzó otras ciudades, además de Medellín, Bogotá, Cali, Barranquilla, Bucaramanga, Cúcuta, Santa Marta, Cartagena, Pereira, Armenia, Manizales y Popayán, según se constata en la información aparecida

8 Camilo Correa, “Pero son en verdad cinco años?”. Micro, n. ${ }^{\circ} 60$ (Medellín, mayo, 1949): 12.

9 Correa, "Pero son", 12.

${ }^{10}$ Carolina Santamaría-Delgado, Vitrolas, rocolas y radioteatros. Hábitos de escucha de la música popular en Medellín, 1930-1950 (Bogotá: Pontificia Universidad Javeriana, Banco de la República, 2014), 90-97.

${ }^{11}$ Fernando Gil Araque (ed.), La crónica y crítica musical en Medellín, 1937-1961 (Medellín: Universidad Eafit, 2013). 
en la misma revista sobre los lugares en que se podía adquirir, aunque no hay cifras sobre los tirajes.

La singular contabilidad que logró transformar 9 años en 5 y una periodicidad variable, en una mensual, ilustra el carácter de Correa, quien, además de su labor como director, gerente y principal redactor en esta publicación, tuvo participación directa en la radiodifusión del país en las décadas de 1930 y 1940 como locutor al frente de programas radiales como Telescopio Radial y Estrellas y Películas; y fue gestor de ambiciosas estrategias publicitarias con las que se buscaba, entre otras cosas, brindar a los anunciantes la oportunidad de llevar sus productos hasta los sitios más lejanos del país. Una de ellas fue el llamado "Viaje perifónico por Colombia" que se realizó en julio de 1939 con el respaldo técnico de la emisora Voz de Antioquia, la retransmisión de la emisora Fuentes $L$ de Cartagena y el cubrimiento semanal de los detalles más destacados por parte del diario El Colombiano ${ }^{12}$.

En este medio escribió, desde 1942, una columna que firmó bajo los pseudónimos de Ego, que también utilizaba en Micro, y de Olimac, anagrama de su nombre. En 1945, colaboró en la formación de Películas Colombianas (Pelco) de la cual fue su primer gerente, remplazado al año siguiente. A finales de 1946, con el camarógrafo francés Charles Riou y la estrella radiofónica Pompilio “Tocayo" Ceballos alquiló los equipos de Ducrane Films, para fundar la Promotora Cinematográfica Nacional (Procinal) ${ }^{13}$, con esta compañía realizó el Noticiero Colombia entre 1947 y 1948, y en 1955 estrenó Colombia linda, de la cual fue director, guionista, editor y camarógrafo y que consistió, en palabras del propio Correa, de una sucesión, apenas hilvanada, de intervenciones de estrellas procedentes de la radiodifusión y la industria fonográfica como el Dueto de Antaño y el humorista Guillermo Zuluaga "Montecristo" ${ }^{14}$, lo que corroboraría la circulación de artistas entre los diferentes medios. También participó en la Agencia Colombiana de Espectáculos y Artistas (Acdeya), empresa dedicada a la representación de músicos; en la creación de una escuela de cine colombiano y en la fundación del primer cine-club de Medellín en $1951^{15}$. Malos manejos en Procinal la llevaron a la quiebra y a Correa a la cárcel en 1956, en donde permaneció ocho meses bajo el cargo de abuso de

12 “Un viaje periférico por Colombia se hará pronto”, El Colombiano, 26 de junio, 1939, 5.

${ }^{13}$ Pilar Duque, La aventura del cine en Medellín (Bogotá, Universidad Nacional de Colombia, 1992), 310.

${ }^{14}$ Martínez Pardo, Historia del cine, 194.

15 “Cine-Club”, El Diario, 12 de junio, 1951, 2. 
confianza continuado. En 1957, viajó a Estados Unidos y se mantuvo alejado de los medios de comunicación ${ }^{16}$.

\section{Crítica cinematográfica y radiofónica}

Publicada, inicialmente, con el objetivo de "agitar el ambiente radial", Micro incluiría rápidamente la sección "Estrellas y Películas", que retomó de su programa radial. Esta sección incluía noticias variadas sobre las estrellas internacionales - tanto de Hollywood como latinoamericanas-, comentarios sobre los estrenos, las proyecciones del Teatro Junín (el más prestigioso de la ciudad en ese momento) e información sobre las salas y el público. Las notas sobre el ámbito radial ocuparon gran número de páginas y se concentraron en las parrillas de programación, los programas radiales, las emisoras y los personajes radiofónicos - locutores, actores y músicos-. Menos espacio tuvieron los deportes, la literatura y el teatro.

En su última etapa, la revista buscó expandir sus horizontes a través de colaboradores internacionales que se encargaron de secciones como: "Cine y radio en el mundo" y "Redactores de Micro en el mundo". Este esfuerzo tuvo como antecedente la sección "Sucedió en la Argentina", aparecida en la segunda etapa de la revista, en la que se informaba sobre los espectáculos más relevantes de la ciudad de Buenos Aires.

"Estrellas y Películas" fue rápidamente nutrida con subsecciones como "Crítica" y "Critiquillas". En la primera, Correa daba su opinión sobre las películas que había visto, a la que agregó, desde el número 13, para cada película, una calificación, que iba de una a cuatro estrellas, basada en la dirección, la interpretación, la fotografía y otros elementos técnicos, y dejaba por fuera su éxito en taquilla. A partir de la edición 29, las estrellas desaparecieron y empezó a utilizar la letra A, de la siguiente forma: $A A A A$ : Excelente. Véala de todas maneras! AAA: Muy buena. Sería bueno que la viera. AA. Buena. No le pesará verla. A. Mediana. Si es usted tolerante...... a............. Nos lavamos las manos, explicación que apareció en todas las ocasiones en que utilizó esta escala.

El comentario que acompañaba esta calificación fue, por lo general, corto, aunque su extensión variaba de 3 a 15 líneas, al cual se sumaba la ficha técnica de la película. Las críticas comenzaban con el nombre del filme, continuaban con el nombre de la empresa productora, si eran películas de Hollywood, o con el país, si eran europeas, seguían con los actores y terminaban con la valoración de la película. El aspecto que más se resaltaba fue la actuación; por

${ }^{16}$ Pilar Duque, Veintiún centavos de cine (Medellín: Gobernación de Antioquia, 1988), 192. 
ejemplo, sobre Servicio de Hotel (Room Service, 1938), calificada con una A, se señaló: Nunca se vio nada tan pésimo en ese teatro. Arturo Puerta, Gustavo Rodas y Camilo Correa pueden dar mitad de partido para la comicidad a esos desafortunados Hermanos Marx. Pero es casi fijo que insistirán" ${ }^{17}$.

En ocasiones, se destacaban la dirección, el guion o el vestuario. De la película El pájaro azul (The Blue Bird, 1940), destacada con la máxima calificación, se planteó: Los honores de este suceso glorioso de Twenty Century Fox se las lleva, indudablemente, el director y el director artístico, que llevaron al cine todo el beneficio del colorido y los recursos escenográficos para lograr una fantasía que difícilmente será superada ${ }^{18}$. Sin embargo, nunca se mencionaron los nombres del director y los directores artísticos; es más, se mencionó en singular al director artístico, cuando esta función la ejercieron dos personas. Lo que muestra el indudable predominio de una tradición impulsada por las publicaciones auspiciadas por los estudios de Hollywood y sus distribuidores, que operaban bajo la lógica del Star System, que destacaba a los actores protagónicos y a las productoras, a diferencia de la crítica moderna, surgida en Francia, Inglaterra y Estados Unidos durante la posguerra, que privilegió a los directores ${ }^{19}$.

Correa en sus críticas pocas veces sustentó sus argumentos y calificaciones. Esto pudo deberse a su falta de formación y erudición fílmica, pero, sobre todo, a la poca extensión de las críticas. No obstante, se debe reconocer que su opinión mantuvo un alto grado de independencia que hizo posible que les diera bajas calificaciones a películas que el Teatro Junín, uno de sus principales anunciantes, promocionaba como una "súper" o como "la mejor comedia del año" o la mejor película de un determinado actor o actriz. También, defendió la idea de que la crítica debía realizar una valoración estrictamente cinematográfica y dejar por fuera los argumentos de carácter moral, comunes en las secciones de espectáculos de algunos periódicos. Y que debía ser imparcial $\mathrm{y}$ formar a los lectores, sin ser muy estricta, dado que

El público desconocedor absoluto de ella, e influenciado por veinte años de publicidad, iba a encontrar recia la crítica que se hiciera, y tal vez malentenderla; nuestra labor es ante todo educativa. Así como al niño hay que enseñarle a leer por sílabas y luego a juntarlas para formar las palabras, en la misma forma al público, niño en nuestro caso, hay que ilustrarle un

${ }^{17}$ Camilo Correa, "Estrellas y películas”, Micro, n.o 44 (Medellín, 29 de enero, 1941): 7.

${ }^{18}$ Camilo Correa, “Estrellas y películas”, Micro, n. 33 (Medellín, 16 de octubre, 1940): 13.

${ }^{19}$ David Bordwell, Making Meaning: Inference and Rhetoric in the Interpretation of Cinema (Cambridge and London: Harvard University Press, 1989), 43-44. 


\begin{abstract}
poco más en los "misterios" del cine, para que luego él mismo comprenda mejor nuestra crítica. A medida que los días corran, iremos haciéndonos más estrictos, sin llegar en ningún caso a la intransigencia, porque conocemos la industria cinematográfica y también el negocio en nuestro medio y por lo mismo comprendemos mejor cuanto luchan nuestros empresarios para llevar a sus salas programas de verdad y también cuando luchan por llevar el público a esas salas a admirar sus programas ${ }^{20}$.
\end{abstract}

Era necesario ayudar a la maduración de la audiencia haciéndola comprender que el cine no era un espectáculo trivial y que las películas debían ser juzgadas por sus elementos técnicos y artísticos: dirección, actuación, guion, fotografía, sonido, a la par que por su valor histórico y social. El cine era, pues, un fenómeno complejo que debía ser valorado con conocimiento de causa; para ello, prometió en la edición 37 la publicación semanal de artículos, escritos por autores calificados, que formaran a ese público infantil y que evitaran que películas de gran calidad y respaldadas por fuertes campañas publicitarias como Lo que el viento se llevó fracasaran en la taquilla, e hicieran evidente la incultura de los medellinenses.

Desde esta perspectiva, el cine como espectáculo moderno debía ser apreciado por un gusto también moderno, pero este gusto no estaba lo suficientemente consolidado y expandido en la Medellín de la década de 1940 y había que formarlo a través de una pedagogía de la mirada que enseñara a la audiencia el valor de la técnica implicada en la realización de una película, para que la juzgara en sí misma como el resultado de procedimientos singulares y específicamente cinematográficos, es decir, se debían construir las condiciones para una valoración de las obras en sí mismas, por fuera de criterios extracinematográficos, sobre todo aquellos de carácter moral que deformaban la mirada del espectador ${ }^{21}$.

En este sentido, se trataba de dar un paso más allá de la sociedad espectadora, que a su vez había dejado atrás la sociedad parroquial. Para Franco Díez, una sociedad parroquial asiste a entretenimientos colectivos que se desarrollan por temporadas y que no están, en la mayoría de los casos, mediados técnicamente; en ellos los asistentes se suelen identificar más con los artistas, que con los personajes o los relatos. En una sociedad espectadora, los ciudadanos asisten cotidianamente a espectáculos públicos mediados técnicamente y están en

${ }^{20}$ Camilo Correa, "Editorial”, Micro, n. ${ }^{\circ} 42$ (Medellín, 21 de diciembre, 1940): 1.

${ }^{21}$ Antoine de Baecque y Thierry Frémaux, “La cinéphilie oul'invention d'une culture”, Vingtième Siècle. Revue d'histoire, n. ${ }^{\circ} 46$ (1995): 139. 
capacidad de sumergirse en los relatos ${ }^{22}$. Lo que Correa pretendía, sin darle ese nombre, era que, en el seno de la sociedad espectadora, se desarrollara la cinefilia, palabra que designa a una "cultura" cinematográfica, entendida como:

[...] un saber adquirido por la experiencia de las películas y de una acción de cultivar [...] el placer cinematográfico. Ella abarca al mismo tiempo la memoria y la capacidad de juzgar adquirida por el contacto de una técnica artística [...] frecuentada durante nuestro esparcimiento como hombres libres $[\ldots]^{23}$.

Así, si la sociedad espectadora requiere de un público que suspenda su incredulidad ante los relatos fílmicos, la cinefilia requiere un doble movimiento, puesto que debe retornar de esta suspensión para juzgar críticamente lo visto.

Es difícil, pues, sostener la posición de que Correa se consideraba a sí mismo un "opinante", como se autodefinió en la entrevista con Martínez Pardo. Es más, su lucha por formar una audiencia conocedora hizo que se comprometiera con la creación de una de las instituciones insignias de la cinefilia: un cine-club que programara las películas que los empresarios consideraban, no sin razón, "demasiado finas", para una ciudad, en que:

Cada día es más notorio que el público está formado por un 99\% de admiradores de Arturo de Córdoba, Cecil B. DeMille y demás simuladores de arte, cuando no por tintanistas y tongolelistas de los que ha creado el gobierno dejando aduanas francas a todas esas basuras mexicanas ${ }^{24}$.

El cine-club debía estar conformado por un número no muy grande de personas que, mediante el pago de una cuota mensual, pudieran ver películas selectas no exhibidas con anterioridad en la ciudad, acceder a una biblioteca especializada, y, posteriormente, desempeñarse como guionistas, directores, camarógrafos y actores de la futura industria cinematográfica colombiana ${ }^{25}$. Correa logró que el Cine-club de Medellín empezara sus actividades en 1951, pero el proyecto tuvo una efímera vida, puesto que pronto se vio enfrentado a la censura eclesiástica, enemigo mucho más poderoso e influyente que

\footnotetext{
${ }^{22}$ Franco Díez, Germán, Mirando solo a la tierra. Cine y sociedad espectadora en Medellín (19001930) (Bogotá: Pontificia Universidad Javeriana, 2013), 44.

${ }^{23}$ Laurent Jullier y Jean-Marc Leveratto, Cinéfilos y cinefilias (Buenos Aires: La Marca, 2012), 11.

${ }^{24}$ Camilo Correa, “Hagamos un cine-club”. Micro, n.o 62 (Medellín, julio, 1949): 63.

25 “Club de cine aficionados”, El Diario, 7 de septiembre, 1949, 2.
} 
los seguidores de los actores Germán Valdés “Tin Tan” o Yolanda Montes "Tongolele" 26.

Mientras publicaba Micro, Correa también ejercía como locutor de La Voz de Antioquia, lo cual lo ponía en la penosa situación de justificar permanentemente que no buscaba favorecer dicha emisora. Con el propósito de hacer explícita su imparcialidad, en el primer número apareció una columna en la que se planteaba la independencia de la revista, soportada en que era financiada por las siete emisoras que funcionaban en la ciudad: La Voz de Antioquia, Emisora Claridad, Ecos de la Montaña, Radio Nutibara, Radio Córdoba, Ecos de Occidente y La Voz del comercio ${ }^{27}$. No obstante, la pretendida imparcialidad de la publicación fue puesta en duda muy pronto, ya que algunas emisoras dejaron de anunciar en sus páginas y fueron constantes las cartas, tanto de personas del medio radial, como de otras ajenas a este, que discutían las posiciones de Correa o las de algunos de sus colaboradores, especialmente de Luis Miguel de Zulategi.

Puede asegurarse que uno de los motivos del descontento contra Micro fueron las ácidas críticas que la revista lanzaba, y cuyo blanco frecuente eran populares locutores como "Martinete"28 o emisoras como Radio Córdoba y La Voz del comercio. Las críticas se referían en ocasiones a aspectos técnicos como la calidad del sonido, el alcance de la transmisión o su inestabilidad, pero en la mayoría de los casos apuntaban al plagio descarado de los artículos de la prensa en los radioperiódicos, la repetición de discos malos, la calidad de los artistas y locutores, y la vulgaridad y el mal gusto de los programas radiados.

Los locutores o speakers fueron con frecuencia reconvenidos por hablar a los gritos, hacer excesivo énfasis en ciertas sílabas o letras o por pronunciar incorrectamente las palabras o confundir unas con otras, todo visto como signo de incultura y considerado grave en tanto la radiodifusión podía propagar todas estas incorrecciones entre los radioescuchas. Radio Córdoba, por ejemplo, fue acusada de ser una cantina radial, por la música que ofrecía y por el ambiente desordenado y vulgar de sus programas. Pero fue La Voz del Comercio la emisora que recibió la crítica más dura; fue acusada por Correa de 18 horas continuas de atentados contra la ética y la estética, en tanto se reunían en ella:

${ }^{26}$ Martínez Pardo, Historia del cine, 223 y Orielly Simanca Castillo, "La censura católica al cine en Medellín: 1936-1955. Una perspectiva de la Iglesia frente a los medios de comunicación”, Historia Crítica, n. 28 (2005): 96-97.

${ }^{27}$ Camilo Correa, "Notas”, Micro, n. ${ }^{\circ} 1$ (Medellín, 15 de febrero, 1940): 3.

${ }^{28}$ Camilo Correa, "Vale la pena escucharse”, Micro, n. 2 (Medellín, 22 de febrero, 1940): 2 y 7. 
todos los malos locutores de la ciudad", los guitarristas desafinados, los cantantes sin talento, "todo cuanto "pato" llega a "nuestros estudios" pasa al micrófono para berrear sus habilidades; los "locutores" se esmeran para dar en cada frase, en cada palabra, la medida de sus capacidades intelectuales; el administrador pone toda su atención para que las dedicatorias enviadas por los oyentes (con los 0.20 [centavos], sean perifoneadas conservando la interesante redacción original [...]. Llega la noche y ahí es cuando se arma la brava; a las 7 p. m. es Troya: parece que los duendes y las brujas vinieran a celebrar sus aquelarres en la estación de la calle Salamina; aquello es el despiporre, el desastre, el desbarajuste; en riguroso turno desfilan todos ante el micrófono (que debe ser de cemento armado si se considera la cantidad de "golpes" que ha resistido) para decir su bestialidad "por cortesía" de alguna firma comercial (que (sic) firmas!!) ${ }^{29}$.

El autor concluye afirmando que se debe remitir este caso a la autoridad competente, que a su juicio, y lo dice de forma irónica, no es otro que el inspector de Higiene. En las "Notas del editor" del número 40 se acusó, en formato de carta abierta, al ministro de Comunicaciones, de atacar a la cultura y la estética a cinco programas pertenecientes a las emisoras Ecos de la montaña, Voz del triunfo y Radio Córdoba, que eran, infortunadamente, muy escuchados por las clases incultas, de lo que se puede concluir su nociva influencia sobre la cultura popular ${ }^{30}$.

En el ámbito musical fueron frecuentes las menciones a la baja calidad de algunos intérpretes profesionales y la tontería y la vulgaridad de los programas de aficionados, que abrían espacio a "perros y gatos" y que, en ocasiones, enterraban las aspiraciones profesionales de aquellos que tenían talento, dada la falta de dirección o de adecuado acompañamiento instrumental, por lo cual Correa planteaba: Si es Ud.AFICIONADO, exija garantías a la Emisora donde actúa; o deje de ser bobo: cante para usted y su familia allá en la casa ${ }^{31}$. En otras ocasiones, el problema era la inmoralidad de lo transmitido como lo demuestran las repetidas peticiones para la salida del aire de una actriz infantil local conocida como la "Shirley antioqueña”, en referencia a Shirley Temple, quien llevaba en 1940 cerca de dos años de apariciones radiales constantes: No hay cuplet pornográfica que no conozca esta niñita; no existe canción de sentido escabroso ignorada por la 'Shirley antioqueña'32, por lo cual se pedía la intervención de las autoridades

${ }^{29}$ Camilo Correa, "Una arcadia feliz”, Micro, n⿳o 8 (Medellín, 13 de abril, 1940): 11.

${ }^{30}$ Camilo Correa, "Notas del editor", Micro, nº 40 (Medellín, 3 de diciembre, 1940): 1.

${ }^{31}$ Camilo Correa, "Inutilidad”, Micro, nº 6 (Medellín, 30 de marzo, 1940): 4.

${ }^{32}$ Camilo Correa, "Recortes", Micro, n. ${ }^{\circ} 2$ (Medellín, 22 de febrero, 1940): 8. 
o, en su defecto, de sus padres para evitar que la radio se constituyera en una corruptora de menores.

No en vano en la primera página del primer número de Micro se hace la siguiente pregunta: "Tenemos censor?" ${ }^{33}$, figura a la cual se le pide tener una actuación real para acabar con el "libertinaje" y el ambiente de "cabaret" de una emisora, al parecer Radio Córdoba, a la cual se acusa de disfrazar de humorismo la miseria de espíritu, el vil comercio y la explotación de las bajas pasiones, con la excusa de complacer al pueblo que, afortunadamente, es mejor que quienes lo buscan complacer. La insatisfacción frente a la acción gubernamental reaparece en varios números; en uno de ellos se plantea que en Medellín sobran tres emisoras:

todo el mundo lo sabe... menos el gobierno porque el gobierno está muy ocupado para ver estos PEQUEÑOS detalles, los pequeños detalles que, poco a poco, dan a un país fama de inculto, de salvaje, de semi-colonial [...]; esas empresas, que pudieran llamarse PIRATAS, son verdaderas sanguijuelas del progreso radial colombiano. Fuera con las licencias (sic) inmerecidas!!!"34.

La preocupación por la censura permite apreciar una de las principales tensiones en la crítica realizada por Correa, si bien apunta a una crítica que valore los aspectos técnicos, artísticos y formales de los programas radiales, se hace presente una valoración en términos de civilización y barbarie, y de moralidad, lo que vuelve a mezclar la ética con la estética de una forma que recuerda a la crítica tradicional.

Retornando al ámbito cinematográfico, los artículos pertenecientes a la sección "Critiquilla" se ocupaban sobre todo de la exhibición y, en menor medida, la producción. En las critiquillas, se atacaron cáusticamente los problemas en las proyecciones -interrupciones, desenfoques-, ya fueran causados por incompetencia de los proyeccionistas o por la deficiencia de los equipos; también se criticó el aumento del precio de la boletería, la incomodidad de las instalaciones, entre otras. Sin embargo, fue la audiencia en general o partes de ella, el blanco principal de Correa.

Consideró que el público de la ciudad no estaba formado para apreciar las películas, pero tampoco lo estaba para asistir a un espectáculo público, ya que solía, entre otras actitudes censurables, comentar en voz alta las películas que

${ }^{33}$ Camilo Correa, “Tenemos censor?”. Micro, n. ${ }^{\circ} 1$ (Medellín, 15 de febrero, 1940): 1-2.

${ }^{34}$ Camilo Correa, “Notas del editor”. Micro, n. 20 (Medellín, 17 de julio, 1940): 4. 
ya había visto en plena función, arruinándoles la sorpresa a sus infortunados vecinos. Las "señoritas" insistían en ir a cine con sombreros "emplumados" o "enflorecidos" que cubrían la pantalla para los espectadores que estaban situados detrás de ellas; mientras los "pillitos", "titinitos", "pisaflores" y "niños lindos" cometían toda clase de atropellos amparándose en la oscuridad y la multitud, lo cual llevó a Correa a solicitar que los agentes de policía fueran trasladados de la galería, en donde a su juicio prácticamente no servían para nada, a la luneta, en donde se escondían entre las sombras un sinnúmero de "rufianes" que ofendían el pudor de las damas con sus comentarios:

las escenas amorosas de la cinta y aun las dramáticas, no merecieron de los piernipeludos de pantalón largo y apellido "respetable y adinerado", otro comentario que el equívoco de mal gusto cuando no el chiste que de vulgar paso a canalla. Ya vale la pena iniciar una campaña en pro del aseo de los cinemas: Medellín es una ciudad con fisonomía de tal y no es cosa de echar a perder nuestro buen nombre por tolerar a unos cuantos peones uniformados de "cachaco"; desgraciadamente podemos decir que la mayoría de tales sinvergüenzas no es de este departamento; desgraciadamente, pues si los malandrines fueran "de la casa”, con más facilidad se les aplicaría el correctivo; sin embargo, quien vive en una casa debe ajustarse a sus costumbres.

Cada espectador puede ser papá del atrevido que no lo tuvo para enseñarle buenos modales ${ }^{35}$.

Las critiquillas contra las "señoritas" y los "piernipeludos" muestran de nuevo un esfuerzo para que ir a cine fuera una práctica en la que la audiencia se concentrara en las películas y las juzgara, y no una excusa para el lucimiento social, el coqueteo o el desorden. Además, muestra que la formación del público por parte del crítico era una labor integral que iba desde su comportamiento en los lugares de exhibición hasta la formación de su gusto cinematográfico. Algo similar ocurría con los radioteatros, pues en sus comentarios hacía llamados de atención sobre el tipo de público habitual en estos espacios que, a diferencia de los cines, eran de ingreso gratuito; hecho que los convertía en lugares convenientes para que los desocupados pasaran sus horas muertas, por lo que Correa pidió nuevamente la intervención de la policía, luego de alegrarse porque, gracias a sus denuncias sobre un "piernipeludo" que "vivía" en los corredores y el salón para el público de La voz de Antioquia, por fin había

${ }^{35}$ Camilo Correa, “Critiquilla”. Micro, n. 26 (Medellín, 28 de agosto, 1940): 14. 
dejado de aparecer por allí, [...] ya solo falta que llegue la bola [carro de la policía] cualquier noche y se llene con los adultos del mismo género que tienen monopolizado el salón que la emisora destinó para "lagente". De lo contrario,es decir, si continúa esa clientela ahí, las personas decentes no podrán asistir a las audiciones sensacionales que se avecinan ${ }^{36}$. En sus comentarios, Correa solicitaba a los directivos de las diferentes estaciones radiales de la ciudad que evitaran la entrada o expulsaran de sus emisoras a este tipo de personas y que solo dejaran la puerta abierta para quienes no fueran un descrédito para la seriedad de estas.

\section{Industria cinematográfica e industria radiofónica en Colombia: utopías y realidades}

Camilo Correa fue un duro crítico de las películas colombianas. Algunos de sus blancos favoritos fueron los documentales promocionales encargados por diversas dependencias estatales en los años 40. Por ejemplo, Colombia documental fue acusado de difundir una imagen de salvajismo del país, cuando su objetivo explícito era mostrar su cara positiva ${ }^{37}$. El cortometraje 12 de octubre fue calificado como ridículo y desacreditador, entre otros motivos, por la incapacidad del director de fotografía de encontrar un rostro bonito entre miles de estudiantes, por las deficiencias de sonido que hacían que la voz del presidente Eduardo Santos se confundiera con la del locutor y por el mal gusto de sobreponer el sonido de una marcha estadounidense a las "vistas" de la bandera colombiana ${ }^{38}$.

Sobre Antioquia monumental planteó:

Queremos ver cine nacional y por ellos decimos esto. Pero queremos ver "cine nacional", no malas películas hechas en Colombia por colombianos. Si el gobierno reincide, nosotros haremos lo propio. Seremos los primeros en aplaudir la primera fotografía animada buena que veamos y no cejaremos en criticar y vapular todo aquello que, con buena o mala intención, trate de hacernos aparecer como ridículos, ignorantes y petulantes ${ }^{39}$.

Ante su desencanto de las películas nacionales, Correa decidió hacer por escrito, años después lo intentaría en celuloide, lo que los demás se habían

\footnotetext{
${ }^{36}$ Camilo Correa, "Píldoras", Micro, n. ${ }^{\circ} 8$ (Medellín, 4 de octubre, 1940): 12.

${ }^{37}$ Camilo Correa, “Critiquilla”, Micro, n. ${ }^{\circ} 23$ (Medellín, 7 de agosto, 1940): 6.

${ }^{38}$ Camilo Correa, "Crítica”, Micro, n.o 43 (Medellín, 22 de enero, 1941): 7.

${ }^{39}$ Camilo Correa, "Crítica”, Micro, n. 10 (Medellín, 27 de abril, 1940): 8.
} 
mostrado incapaces de realizar. Bajo el título de Ficción cinematográfica publicó un manifiesto de sus intenciones; en ese artículo narra una visita a la productora ficticia Ciansa (Cinematografía Antioqueña S. A.), fundada en 1941. Esta compañía, según su relato, produjo una película titulada Bambuco a la que siguieron, a un ritmo de una película trimestral, Lejos del nido, Hace tiempos, Rosalba, Guabina, Calzones, El maíz, Tonuzco y Barequeros, las dos primeras basadas en novelas y todas de carácter folclórico y de fácil filmación y edición, pero hechas con calidad para permitir realización más adelante de películas de carácter internacional, para lo cual se habían importado equipos modernos y traído técnicos extranjeros para que capacitaran a los colombianos. Ciansa tenía en preparación Ricaurte en San Mateo, con la cual se arriesgaban dentro del cine histórico, con sus exigencias locativas, en vestuario y en extras; esta película estaría a cargo de Hernando Téllez, Camilo Correa o un candidato anónimo. Esta ficción termina con una entrevista al director de la productora, en la cual Ego, seudónimo de Correa, solicita a su entrevistado: Por qué no lo aconseja a nuestro director (nuestro por partida (sic) noble), pues lo es de MICRO y de películas "CIANSA" que aumente el sueldo del cronista cinematográfico a ver si el pobre puede casarse? $?^{40}$.

Este texto, en el cual Correa aparece en cuatro papeles: periodista, director de una productora, director de una revista y posible realizador de una película, hace visible las ideas que tenía este personaje sobre la industria fílmica en Colombia. Para él, Medellín tenía el potencial para transformarse en una copia a menor escala de Hollywood, ya que disponía de luz natural para filmar durante todo el año, su clima era benigno, la ubicación geográfica era adecuada, los paisajes variados, los medellinenses tenían un espíritu artístico y empresarial, las mujeres eran hermosas; todo ello la hacía la mejor ciudad para concentrar la producción cinematográfica nacional, la cual debía ser constante -la ficticia Ciansa producía una película cada tres meses-,y empezar con películas fáciles y baratas de hacer, pero que atrajeran con facilidad a la audiencia a través del gancho comercial de la música popular y las adaptaciones literarias de obras famosas; todo esto sentaría las bases de una industria que luego se lanzaría a realizar películas serias o internacionales para distribuir masivamente fuera del país; esta seriedad parecía estar asociada a las películas históricas. Sintetizando, se trataba de hacer, en un primer momento, películas cuya inversión pudiera ser recuperada en el mercado nacional y que permitieran la capitalización de

${ }^{40}$ Camilo Correa, “Ficción cinematográfica”. Micro, n. ${ }^{28}$ (Medellín, 10 de septiembre, 1940): 14. 
las compañías productoras, para, luego, realizar películas más ambiciosas que compitieran en el mercado internacional.

Lo que Correa criticó en sus escritos no fue entonces la realización de las películas promocionales y folclóricas, que consideraba necesarias en un primer momento, sino su mala calidad; al referirse a Allá en el trapiche, señaló que lo único que tuvo de cine fue el celuloide, ya que hasta el título fue desacertado ya que no aparecía ninguna molienda: Título arbitrario, argumento analfabeto, actuación bochornosa, dirección cafre, sonido y sincronización rudimentarios. Un desastre en suma $a^{41}$. A pesar de ello, la película en su opinión fue útil dado que produjo ganancias y alentó proyectos de este tipo, es decir, ayudó a impulsar, aunque fuera un poco, la industria cinematográfica colombiana.

La producción de películas folclóricas no se oponía al deseo por la modernidad, por el contrario, el folclor era el punto de partida de la modernidad cinematográfica en Colombia, ya que la apuesta por un cine nacional remitía al interés por construir una industria sólida, rentable y estable más que a una apuesta ideológica o formal ${ }^{42}$. Tanto Correa como las compañías cinematográficas del momento (Ducrane Films, Calvo Film Company, Patria Films, Cofilma) compartían implícitamente una misma intuición: lo "nacional-popular" debía vincularse a los medios de comunicación masiva ${ }^{43}$, o de una forma más radical aún: lo "nacional-popular" era ya impensable sin lo masivo ${ }^{44}$, como lo ilustraba el énfasis en las películas basadas en las historias y las músicas nacionales. Lo que Correa no toleraba era justamente que se le ofreciera a un público "inculto", pero seguidor de cinematografías profesionales como la estadounidense, la francesa, la mexicana y la argentina, productos que, dadas sus deficiencias en dirección, interpretación, fotografía y técnica cinematográfica, sepultaban las esperanzas de una industria propia que compitiera exitosamente en el mercado nacional e internacional. Aunque sus juicios no estuvieron exentos de polémica; por ejemplo, fue acusado de haber destrozado con sus críticas la película La canción de mi tierra y, por

${ }^{41}$ Camilo Correa, “Colombia tiene ya su propio cine!”. Micro, n. 52 (Medellín, julio, 1943): 9. ${ }^{42}$ María Antonia Vélez, "Empezar por la piscina”, Artefacto, n. ${ }^{0} 12$ (2007): 27-31.

${ }^{43}$ María Antonia Vélez, "En busca del público: Patria Films y los primeros años del cine sonoro en Colombia”, en Versiones, subversiones y representaciones del cine colombiano. Investigaciones recientes, editado por Pedro Adrián Zuluaga (Bogotá: Museo Nacional, Fundación Patrimonio Fílmico Colombiano, 2008), 180-218.

${ }^{44}$ Jesús Martín Barbero, De los medios a las mediaciones: comunicación, cultura y hegemonía (Bogotá: Convenio Andrés Bello, 2003), 205-206. 
ende, de haber perjudicado notablemente su recaudación, todo debido a que la compañía productora no le había dado el dinero que exigía por sus labores como publicista ${ }^{45}$.

Para Correa la consolidación de la cinematografía colombiana solo requería un elemento, la inversión capitalista, ya que todas las otras condiciones estaban dadas, tal vez no en otros lugares del país, pero sí en Medellín. Esta inversión serviría para traer técnicos extranjeros que enseñaran a los colombianos dispuestos a aprender; estos técnicos luego de su labor pedagógica debían abandonar el país; el capital también permitiría la importación de equipos modernos. El tiempo demostró que los técnicos nacionales no lograron reemplazar a los extranjeros, quienes fueron los responsables de la mayor parte de las películas realizadas en la década de 1940 y, en la mayoría de los casos, tampoco se logró adquirir equipos de última generación, lo cual provocó múltiples inconvenientes técnicos para el incipiente cine sonoro colombiano. No obstante, lo interesante aquí es que el anhelo de un cine nacional no implicó el deseo de cerrarse al contacto internacional, por el contrario, este contacto era condición necesaria para la formación de una verdadera industria, al tiempo que la distribución internacional de las películas filmadas fue considerada como indispensable para su consolidación y estabilidad.

Las grandes compañías internacionales fueron acusadas por Micro de ser enemigas de la producción local, en tanto les habían hecho creer a los colombianos que no estaban capacitados para hacer cine, con el objetivo de evitar la competencia. En este sentido, los inversionistas nacionales permanecían por fuera de un lucrativo negocio, como lo demostraba que películas como la mexicana Allá en el rancho grande (1936) y la argentina $\mathrm{La}$ vida es un tango (1939) alcanzaran utilidades de entre 30 y 40 mil pesos solo en las salas colombianas. Correa consideraba que una película colombiana podría duplicar o triplicar estas cifras en el mercado interno y aun le quedaría el mercado internacional para obtener mayores ganancias ${ }^{46}$. Lo que llama la atención de estas afirmaciones es la falta de argumentos que fundamentaran estos generosos cálculos o, en otras palabras, la falta de bases sólidas para justificar la inversión de los capitalistas que tanto se pedía. No obstante, la producción fílmica no era solo un asunto económico, puesto que allí estaba en juego la imagen de Colombia, por lo cual debía ser regulada por el Estado, que

${ }^{45}$ Hernando Salcedo Silva, Crónicas del cine colombiano 1897-1950 (Bogotá: Carlos Valencia Editores, 1981), 164.

${ }^{46}$ Camilo Correa, “Por un cine nacional”. Micro, n. 59 (Medellín, septiembre, 1944): 3-4. 
debía fijar unos parámetros mínimos de calidad para la exportación e impedir que el folclor patrio fuera denigrado y las películas fueran objeto de las burlas del público extranjero que estaba habituado a ver películas técnicamente correctas. Se evidencia aquí una segunda tensión en el ejercicio crítico de Correa y su relación con el cine nacional, en tanto el juicio estético es desplazado por una valoración concentrada en la defensa del orgullo patrio.

La discusión sobre el cine colombiano y su relación con la música, sobre todo con las músicas andinas, en la década de 1940, ha sido vinculada por los críticos y académicos a la subordinación del cine a la radiodifusión. Salcedo Silva ${ }^{47}$ ha considerado que muchas de las películas de esta época no eran más que números musicales organizados de forma similar a un programa radial, solo que filmados. Estas películas buscaban beneficiarse de la seducción que sobre el público ejercían las canciones y los cantantes de moda, incluso la película Golpe de gracia (1944) fue patrocinada por cuatro emisoras bogotanas ${ }^{48}$ y su historia fue ambientada en el mundo del radioteatro, lo cual sirvió de pretexto para presentar cuatro números musicales. Como se mencionó, el mismo Correa haría parte de esta tendencia en el único largometraje que dirigió: Colombia linda.

En este punto es necesario mencionar que, si bien el cine antecedió a la radiodifusión y logró formar rápidamente un público amplio que asistía con regularidad a las diferentes salas, la falta de una industria fílmica y, por ende, de una producción constante y un star system local hicieron que la radio y la industria fonográfica prestaran artistas e incluso formatos que el cine nacional apropió según sus posibilidades, más aún si este era un modelo que ya había sido probado con éxito en Argentina y México, los únicos países latinoamericanos con una producción cinematográfica de carácter industrial.

Trabajos de historiadores del cine como Rick Altman han planteado que este medio ha pasado por discontinuidades y crisis tan profundas que hacen necesario pensar al cine, no como un medio o expresión unificada y homogénea, sino como una práctica plural; una de estas crisis fue provocada por la llegada del sonido, que hizo que una película como The Jazz Singer, considerada el primer largometraje sonoro, pueda ser clasificada tanto como una película como la grabación de media docena de canciones en un disco Vitaphone ampliado ${ }^{49}$. De

\footnotetext{
${ }^{47}$ Salcedo Silva, Crónicas del cine191-192.

48 Omar Méndez, "Las apariencias engañan, Film Mundial”, El Liberal, 2 y 8 de diciembre, 1943.

${ }^{49}$ Rick Altman, "Otra forma de pensar la historia (del cine): un modelo de crisis”. Archivos de la Filmoteca, n.․ㅡ 22 (1996): 12.
} 
forma similar, André Gaudreault ${ }^{50}$ ha argumentado que la historia de los medios, las artes y los espectáculos se enriquecería con la introducción de la noción de paradigma cultural, la cual hace referencia a un sistema múltiple de prácticas generadoras de sentido que hace posible afirmar, por ejemplo, que muchas de las películas que presentan trucos de magia y actos de saltimbanquis forman parte del paradigma cultural de los espectáculos de escena más que del cine, el cual tendría un carácter narrativo. A título de hipótesis para futuras investigaciones, se podría plantear que en una cinematografía periférica como la colombiana, la llegada del cine provocó tal crisis que reconfiguró el ecosistema mediático y las películas sonoras nacionales de la década del 40 pertenecen tanto al cine como a un paradigma cultural que se podría denominar como de reproducción técnica del sonido, el cual incluiría prácticas como la radiodifusión, la industria fonográfica y el cine sonoro, pero esto requeriría la revisión detallada de las películas y no de la revista Micro que es el objeto de este artículo.

En el caso de la radiodifusión, los primeros años de su actividad en el país la inscribieron en el paradigma cultural previo ligado a las representaciones hechas para auditorios y teatros - espectáculos de escena-. La misma radio se definía a sí misma como la oportunidad de ofrecer contenidos "al gran auditorio de las naciones". Durante la década de 1940, Correa, a través de su revista Micro, se encargó de hacer un juicioso seguimiento al proceso de consolidación de la radiodifusión en Colombia y en Medellín, en particular. Prestó especial atención a las emisoras que estaban al aire, a la calidad de los programas que ofrecían y a la idoneidad de las personas que se encontraban frente al micrófono. Para inicios de esta década, Colombia contaba con un buen número de emisoras establecidas en diferentes ciudades del país. En uno de sus artículos, llamó la atención sobre la rentabilidad económica que estaba evidenciando este medio de comunicación y entretenimiento y, al mismo tiempo, lanzó una voz de alarma respecto al número de emisoras que se encontraban al aire en el momento, al afirmar que tenemos superproducción (o "sobrecarga") deempresas de broadcasting $g^{51}$.

La conformación de las cadenas radiales hacia el final de la década, Cadena Radial Colombiana (Ca-Ra-Col) en 1948 y la Radio Cadena Nacional (RCN) en 1949, dejó claro el carácter industrial de esta actividad, así como la fuerte relación existente entre publicidad y el carácter de espectáculo que daban las emisoras a los programas que ofrecían en los horarios estelares, en los cuales

${ }^{50}$ André Gaudreault, Cinéma et attraction. Pour une nouvelle histoire du cinématographe (París: CNRS, 2008), 113-116.

${ }^{51}$ Camilo Correa, "Emisoras colombianas". Micro, n. 35 (Medellín, 29 de octubre, 1940): 3. 
fue fundamental el radioteatro como espacio por el que desfilaban los actores, músicos y cantantes del momento. Así se comenzó a perfilar un circuito artístico que permitía a los artistas circular entre el teatro, el cine y la radio y que, incluso, les facilitó a las emisoras apoyarse en los recursos locativos y logísticos de que disponían los teatros de la ciudad, como cuando fue necesario usar los teatros de Cine Colombia para la presentación de los artistas exclusivos que hacían parte de los programas patrocinados por la empresa Kresto ${ }^{52}$.

Es posible, también, comprender la situación de Medellín para ese periodo desde las páginas de Micro. En uno de sus escritos, Correa reclamaba con urgencia el establecimiento de radioteatros, al señalar que, en países como Argentina, Cuba y Uruguay, existían en buen número este tipo de recintos que servían como escenario de lanzamiento de artistas que luego triunfaron en el cine. Asimismo, aseguraba con cierto descontento que, en ese aspecto, nuestro país se encontraba a la zaga incluso de otros países latinoamericanos más pequeños. Y, ante el notorio incremento en el número de emisoras al aire se atrevió a sugerir la construcción de la Radio City en Medellín: Es casi seguro que nunca rebajaremos aquí de seis estaciones; para el público y para las mismas empresas, la conveniencia está en que esas estaciones estén lo más cerca posible unas de otras ${ }^{53}$.

La participación de Camilo Correa en la radiodifusión, el cine, los periódicos y las revistas, y su rol de crítico le permitieron llegar a una comprensión intuitiva del carácter sistémico de los medios. Para Carlos Scolari ${ }^{54}$, la ecología de los medios o Media Ecology estudia los medios de comunicación como entornos o ambientes. En la medida en que estos pueden pensarse como tecnologías que entrañan procesos de cambio técnico y sociocultural, la idea de ecosistema se refuerza, puesto que el ingreso de un nuevo elemento - como los largometrajes sonoros colombianos, por ejemplo - no se presenta como una simple adición, sino dentro de una lógica ecosistémica, en tanto los medios emergentes no se limitan a ser añadidos a lo que ya existía, sino que su aparición e integración cambian todo el entorno. El papel desempeñado por una revista como Micro durante la década de 1940 puede ser interpretado desde la perspectiva planteada por la ecología de los medios en tanto permite evidenciar el entorno constituido a partir de la confluencia de lo impreso, lo cinematográfico y lo

${ }^{52}$ Camilo Correa, "Primera audición de la Cadena (sic) Cresto". Micro, n. ${ }^{\circ} 8$ (Medellín, 13 abril, 1940): 13.

${ }^{33}$ Camilo Correa, "Notas”. Micro, n.․ㅜ 4 (Medellín, 7 de marzo, 1940): 3.

${ }^{54}$ Carlo Scolari, "Los ecos de McLuhan: ecología de los medios, semiótica e interfaces”. Palabra Clave 18, n, ${ }^{\circ} 3$ (2015): 1025-1056. 
radial, así como las prácticas empresariales, de consumo y de formación de públicos.

\section{Para concluir}

En la etapa final de la revista, Camilo Correa seguía empecinado en buscar señales de un doble nacimiento: por un lado, el de un público cinematográfico con un comportamiento intachable en las salas y que, al mismo tiempo, supiera juzgar artística y técnicamente las películas y, por el otro, el de una industria cinematográfica colombiana. En el último número de la publicación aparecieron dos artículos que permiten cerrar esta reflexión; en el primero ${ }^{55}$, calificaba a la audiencia de ignorante y de amante de la bazofia fílmica; en el segundo, acusó al camarógrafo austriaco de ascendencia judía Hans Brückner, de ser una de las principales razones del fracaso de las compañías colombianas, gracias a su deslealtad típica de una raza de mercaderes,${ }^{56}$ afirmación aún más infortunada teniendo en cuenta la cercanía del holocausto.

En los dos textos, es evidente la desilusión de Camilo Correa, consciente ya, en 1949, de que su trabajo por formar núcleos cinéfilos era inútil ante el gusto del público por “Tin Tan”, Jorge Negrete o la "Tongolele”, y que sus esfuerzos por el surgimiento del cine nacional chocaban con el desinterés de los potenciales inversores y con las supuestas ruindades de quienes participaban en las pocas películas estrenadas. No obstante, Correa fue su peor enemigo, su crítica fue virulenta y, en general, acertada con todos, menos con él mismo, lo que lo condujo a embarcarse en proyectos cada vez más quiméricos que lo llevarían a la cárcel y cerrarían definitivamente su participación en los medios de comunicación de masas.

Sin embargo, esto no le resta valor a una labor que ayudó a formar un lector informado, que estaba al tanto de los acontecimientos más relevantes de sus estrellas, del estreno de las grandes producciones en los teatros locales y que, además, podía acceder a otra información sobre el mundo cinematográfico. En este sentido, Micro daba directrices sobre qué ver, dónde y cómo, pues, como lo reiteraba, el crítico debía formar integralmente al público y esta formación abarcaba desde el comportamiento adecuado en los lugares de exhibición hasta la valoración de los aspectos "técnicos" y "artísticos" de las películas. También, se hace evidente la importancia de la historia para pensar el presente, en tanto las discusiones sobre el deber ser de una producción nacional cinematográfica

${ }^{55}$ Camilo Correa, “Hagamos un cine-club”. Micro, n.o 62 (Medellín, julio, 1949): 63.

${ }^{56}$ Camilo Correa, “Herr Bruckner y el cine nacional”. Micro, n. ${ }^{\circ} 62$ (Medellín, julio, 1949): 62. 
de carácter industrial, en la cual lo moderno no riñe con lo local, se mantiene vigente hoy, con variaciones, en el marco del crecimiento en el número de realizaciones colombianas de las últimas dos décadas.

Micro realizó una labor similar en el campo de la radiodifusión. La revista le proporcionaba, al lector y radio-escucha, información sobre las emisoras y sus programas, desde la parrilla de programación, hasta los anuncios de los artistas internacionales que se presentaban ante sus micrófonos, así como datos biográficos de los locutores, e información técnica sobre la potencia y el alcance de las emisoras. Micro se esforzó en trazar directrices para la industria radial, sobre todo para su profesionalización, que implicaba no solo su conversión en empresas comerciales, sino también la preocupación por el buen decir de los locutores y la alta calidad de las presentaciones musicales en vivo, así como la estabilidad de su señal. En definitiva, se trataba de hacer de la radio un medio rentable económicamente, pero también artística y técnicamente relevante. A pesar de que Correa criticó en múltiples ocasiones el funcionamiento radial, también es claro que, a diferencia de la cinematografía, la radiodifusión colombiana sí se constituyó en una industria viable justo en la década en que se editó Micro.

\section{Referencias bibliográficas}

\section{Fuentes primarias}

\section{Publicaciones seriadas}

El Colombiano [Medellín], 1939.

El Diario [Medellín], 1949, 1951.

El Liberal [Bogotá], 1943.

Micro [Medellín], 1940-1949.

\section{Fuentes secundarias}

AA. VV. Cuadernos de Cine Colombiano, n⿳丷ㅜ 22 (2015).

Altman, Rick. "Otra forma de pensar la historia (del cine) un modelo de crisis". Archivos de la Filmoteca, n. 22 (1996): 6-19.

Baecque, Antoine de y Thierry Frémaux. "La cinéphile ou l'invention d'une culture". Vingtième Siècle. Revue d'histoire, n. ${ }^{\circ} 46$ (1995): 133-142.

Bordwell, David. Making Meaning: Inference and Rhetoric in the Interpretation of Cinema. Cambridge and London: Harvard University Press, 1989. 
Calderón Acero, Camilo. "Páginas de cine: el aporte desde Bogotá". Bogotá filmica. Ensayos sobre cine y patrimonio cultural, editado por Sergio Becerra. Bogotá: Alcaldía Mayor de Bogotá, 2012, 270-297.

Castrillón Gallego, Catalina. "La actividad radial colombiana a través de algunos periódicos y revistas, 1928-1950”. Revista Colombiana de Antropología 47, n.o 1 (2011): 137-154.

Castrillón Gallego, Catalina. Todo viene y todo sale por las ondas. Formación y consolidación de la radiodifusión colombiana, 1929-1954. Medellín: Universidad de Antioquia, Universidad Nacional de Colombia, sede Medellín, 2015.

Chartier, Roger. El mundo como representación. Historia cultural entre práctica y representación. Barcelona: Gedisa, 1996.

Chartier, Roger. La historia o la lectura del tiempo. Barcelona: Gedisa, 2007.

Concha Henao, Álvaro. Historia social del cine en Colombia. Tomo 1, 1897-1929. Bogotá: Publicaciones Black Maria, 2014.

Duque, Pilar. Veintiún centavos de cine. Medellín: Gobernación de Antioquia, 1988.

Duque, Pilar. La aventura del cine en Medellín. Bogotá: Universidad Nacional de Colombia, El Áncora Editores, 1992.

Franco Díez, Germán. Mirando solo a la tierra. Cine y sociedad espectadora en Medellín (1900-1930). Bogotá: Pontificia Universidad Javeriana, 2013.

Gaudreault, André. Cinéma et attraction. Pour une nouvelle histoire du cinématographe. París: CNRS, 2008.

Gil Araque, Fernando (ed.). La crónica y crítica musical en Medellín, 1937-1961, Medellín: Universidad Eafit, 2013.

Jullier, Laurent Jullier y Jean-Marc Leveratto. Cinéfilos y cinefilias. Buenos Aires: La Marca Editora, 2012.

Martín Barbero, Jesús. De los medios a las mediaciones: comunicación, cultura y hegemonía. Bogotá: Convenio Andrés Bello, 2003.

Martínez Pardo, Hernando. Historia del cine colombiano. Bogotá: Editorial América Latina, 1978.

Salcedo Silva, Hernando. Crónicas del cine colombiano 1897-1950. Bogotá: Carlos Valencia Editores, 1981.

Santamaría-Delgado, Carolina. Vitrolas, rocolas y radioteatros. Hábitos de escucha de la música popular en Medellín, 1930-1950. Bogotá: Pontificia Universidad Javeriana, 2014.

Scolari, Carlo. "Los ecos de McLuhan: ecología de los medios, semiótica e interfaces”. Palabra Clave 18, n.․ 3 (2015): 1025-1056.

Simanca Castillo, Orielly. "La censura católica al cine en Medellín: 1936-1955. Una perspectiva de la Iglesia frente a los medios de comunicación". Historia Crítica, n. 28 (2005): 81-104.

Vélez Serna, María Antonia. “Transmutaciones de una caja negra: lo nacional en el cine colombiano, según los críticos". En Los pasos sobre las huellas: ensayos sobre crítica de arte. Bogotá: Universidad de los Andes, Ministerio de Cultura, 2007: 63-80. Vélez Serna, María Antonia. “Empezar por la piscina”.Artefacto,n.․12 (2007): 27-31. 
Vélez Serna, María Antonia. "En busca del público: Patria Films y los primeros años del cine sonoro en Colombia”. En: Versiones, subversiones y representaciones del cine colombiano. Investigaciones recientes, editado por Pedro Adrián Zuluaga. Bogotá: Museo Nacional, Fundación Patrimonio Fílmico, 2008, 180-218.

Zuluaga, Pedro Adrián. "Revistas de cine en Colombia. La otra misma historia". Cuadernos de Cine Colombiano, n.․ 6 (2005): 32-49.

Zuluaga, Pedro Adrián. Cine colombiano: cánones y discursos dominantes. Bogotá: Cinemateca Distrital, 2013.

Zuluaga, Pedro Adrián. "Cine colombiano: las garras de oro del canon”. Mediaciones, ก. 14 (2015): $150-161$. 
